\title{
Continuous professional development for psychiatrists
}

\author{
Burden or help
}

\author{
Mike Harris
}

An encounter with a colleague at a conference where I was presenting a paper on the benefits of continuous professional development (CPD) gave me cause to worry about CPD. He told me that CPD was the greatest cause of his demoralisation in that he felt the targets were unachievable for a busy, overworked and under-resourced consultant. He worried that a failure to achieve the targets would render him at a disadvantage unfortunately, he had not been to my lecture but to a parallel session.

The College seriously started to develop a CPD policy in 1991. The motives for this appeared to be recognition that some members of our profession had become isolated, out-dated and too demotivated to seek assistance, that the public had an increasing expectation of a professional body to encourage if not demand higher standards of the members of that profession, a belief that if the Colleges did not 'get their own house in order' Government would legislate, that it was a prime purpose of the College to be promoting continuing education and that while we spend seven or eight years in training grades we will spend thirty or more years as consultants or permanent grade specialists.

The original members of the working party. Drs Richard Williams, James Higgins and Professor Sydney Brandon, had a recent SCOPME (Standing Committee on Postgraduate Medical and Dental Education) report demonstrating the very variable uptake of study leave by different medical groups and the recent reports by the Australian and New Zealand College and the American Psychiatric Association. The SCOPME report, worryingly, indicated that a significant number of consultants and even more associate specialists took very little study leave and some no time. As a result the College developed CME (Continuing Medical Education) guidelines which were later changed to CPD. This was not just a semantic change but a recognition that ongoing education should represent true professional development.

The Royal College of Psychiatrists' policy development has been mirrored by the other colleges. Many people will be aware of the current development in some colleges of 'White lists' of people who are up to date in their CME/CPD, an indication of the direction this movement is going in

Within our College we have developed a formula which we believe represents a minimal requirement compatible with keeping up to date. The 150 hours does not represent an unrealistic aim. The demand is for 100 hours of private study per year (self-monitored and self-regulated) which for most of us will be reading at home. The other 50 hours are split with 30 hours to be spent per year in clinical audit, case conferences and journal clubs, activities that we should be doing especially if we have trainees. and 20 hours split between skills acquisition such as workshops and talks, meetings and lectures, of which only 10 hours needs to be spent away from one's home base. The committee felt this represented a good balance, ensuring not too demanding a time commitment while enabling and encouraging each of us to spend time training with local colleagues and meeting colleagues away from our home area. If this commitment truly represented a minimum it surely must be equally applicable to part-timers as full-timers. The need for knowledge is the same whether treating (or in the case of Mental Health Act Commission second opinion approved doctors or tribunal doctors assessing) patients for one hour or $\mathbf{4 0}$ hours per week.

I have indicated that CPD should be seen as an opportunity not a threat. The opportunity to take time out of one's work schedule for training should be seized and if employers are too demanding take them to task. The chief executive or medical director of the trust will be equally liable as the employee if there is a disaster and no or inadequate time had been allowed for training, audit or development. It is those very doctors who are most hard pressed who are in need of the protection that a properly worked out and organised CPD programme will bring. The opportunity to have time to compare services with colleagues elsewhere, to read about the latest developments, to have time to reflect and plan one's own practice is essential if we are to 
practise to the highest standards for the benefit of our patients and not become idiosyncratic, isolated and maybe even depressed. Having a formal standard in place should serve not to pressure the individual doctor but pressure their employers (via the contracting process and out of fear of litigation) to enable and empower them.

How then to organise such a programme. CPD should ideally be based on an individual review highlighting the doctor's personal needs, areas of weakness, areas in which knowledge needs consolidation and areas in which further development is indicated. The programme should be planned and incorporate elements of the individual's personal development ideals, the needs for the service, elements for updating and elements which represent the employers needs. Such a review should be undertaken with someone else. either a manager (clinical or medical director) or a colleague and reviewed at the end of each year to see if CPD targets have been achieved and whether they have produced benefit for the doctor, the organisation or most importantly the patients.

Finally, the whole process must be owned by the individual doctor who needs to see the benefit to him or herself and his or her patients. CPD should not be another source of stress but a means to alleviate it. CPD is self-monitored and queries can be resolved by discussion within your trust, with the Deputy Regional Advisor (CPD) or by the CPD department at the College.

MIKE HARRIS, Sub-Dean, ConvenorCPDCertification Subgroup Medical Director, St Andrew's Hospital, Billing Road, Northampton NN1 5DG

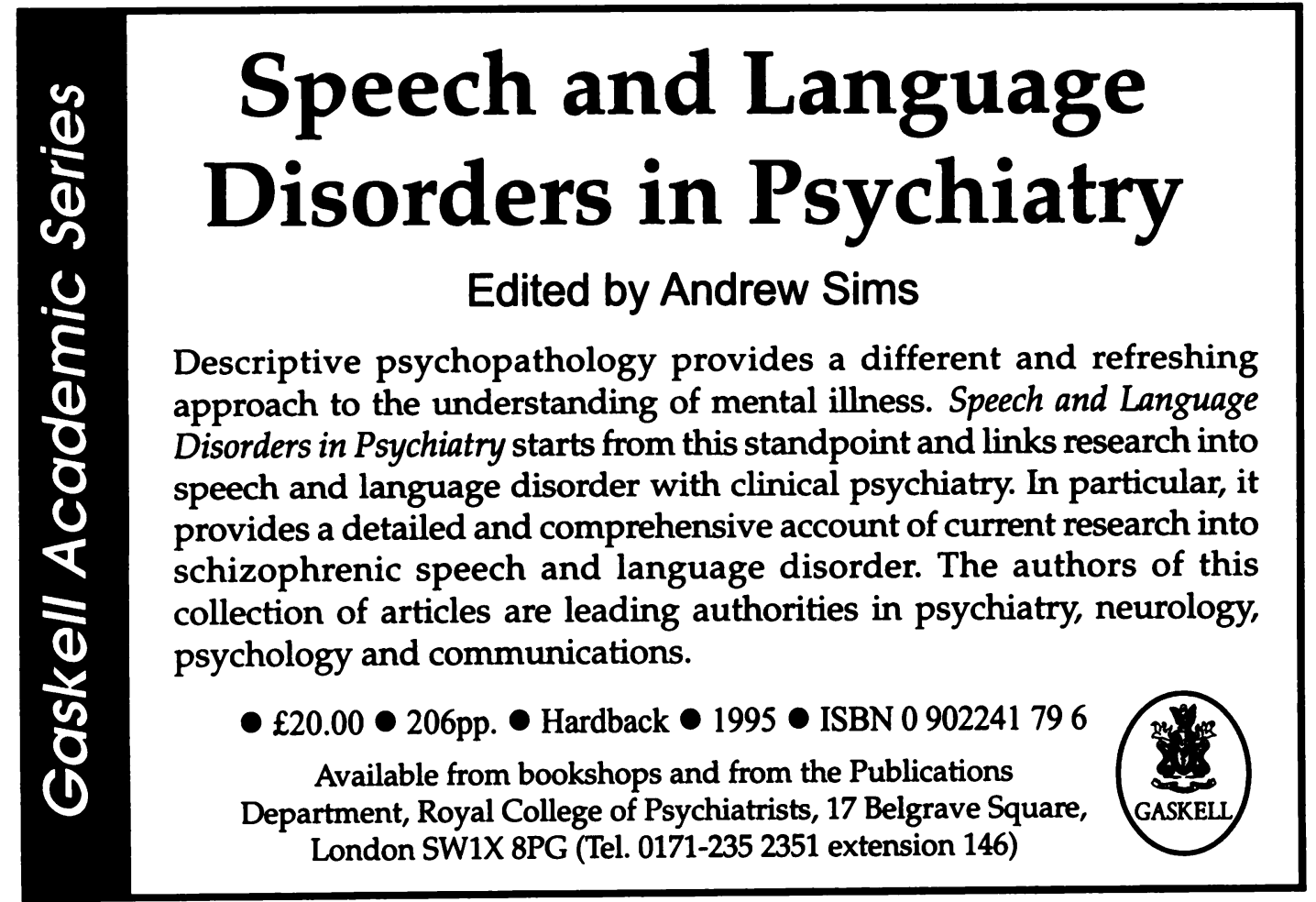

